\title{
Highly pathogenic avian influenza A(H5N8) outbreaks: protection and management of exposed people in Europe, 2014/15 and 2016
}

C Adlhoch ${ }^{1}$, IH Brown ${ }^{2}$, SG Angelova ${ }^{3}$, Á Bálint 4 , R Bouwstra 5 , S Buda ${ }^{6}$, MR Castrucci 7 , G Dabrera 8 , Á Dán ${ }^{4}$, C Grund 9 , T Harder $^{9}$, W van der Hoek ${ }^{10}$, K Krisztalovics ${ }^{11}$, F Parry-Ford ${ }^{8}$, R Popescu ${ }^{12}$, A Wallensten ${ }^{13}$, A Zdravkova ${ }^{14}$, S Zohari ${ }^{15}$, S Tsolova ${ }^{1}$, P Penttinen ${ }^{1}$

1. European Centre for Disease Prevention and Control (ECDC), Stockholm, Sweden

2. Animal and Plant Health Agency (APHA), Weybridge, United Kingdom

3. National Centre of Infectious and Parasitic Diseases, Sofia, Bulgaria

4. National Food Chain Safety Office (NEBIH), Budapest, Hungary

5. GD Animal Health Deventer, Netherlands

6. Robert Koch Institute (RKI), Berlin, Germany

7. Istituto Superiore di Sanita (ISS), Rome, Italy

8. Public Health England (PHE), London, United Kingdom

9. Friedrich-Loeffler-Institut (FLI), Federal Research Institute for Animal Health, Greifswald-Insel Riems, Germany

10. National Institute for Public Health and the Environment (RIVM), Bilthoven, the Netherlands

11. National Center for Epidemiology, Budapest, Hungary

12. National Institute of Public Health, Bucharest, Romania

13. The Public Health Agency of Sweden, Stockholm, Sweden

14. Bulgarian Food Safety Agency, Sofia, Bulgaria

15. National Veterinary Institute (SVA), Uppsala, Sweden

Correspondence: Cornelia Adlhoch (cornelia.adlhoch@ecdc.europa.eu)

Citation style for this article:

Adlhoch C, Brown IH, Angelova SG, Bálint Á, Bouwstra R, Buda S, Castrucci MR, Dabrera G, Dán Á, Grund C, Harder T, van der Hoek W, Krisztalovics K, Parry-Ford F, Popescu R, Wallensten A, Zdravkova A, Zohari S, Tsolova S, Penttinen P. Highly pathogenic avian influenza A(H5N8) outbreaks: protection and management of exposed people in Europe, 2014/15 and 2016. Euro Surveill. 2016;21(49):pii=30419. DOI: http://dx.doi.org/10.2807/1560-7917.ES.2016.21.49.30419

Introduction of highly pathogenic avian influenza ( $\mathrm{HPAl})$ virus $\mathrm{A}\left(\mathrm{H}_{5} \mathrm{~N} 8\right)$ into Europe prompted animal and human health experts to implement protective measures to prevent transmission to humans. We describe the situation in 2016 and list public health measures and recommendations in place. We summarise critical interfaces identified during the $\mathrm{A}\left(\mathrm{H}_{5} \mathrm{~N}_{1}\right)$ and $\mathrm{A}\left(\mathrm{H}_{5} \mathrm{~N} 8\right)$ outbreaks in 2014/15. Rapid exchange of information between the animal and human health sectors is critical for a timely, effective and efficient response.

\section{Avian influenza A(H5N8) situation in Europe, December 2016}

In September 2016, the Food and Agriculture Organization (FAO) of the United Nations raised awareness for the potential reintroduction of highly pathogenic avian influenza ( $\mathrm{HPAl}$ ) virus $\mathrm{A}\left(\mathrm{H}_{5} \mathrm{~N} 8\right)$ to Europe after the detection in a wild swan in the Tyva Republic, Russia, in June 2016. A potential spread of the virus was assumed via the migratory bird routes of duck, geese and swans [1]. The communication followed earlier reports in 2016, of $\mathrm{A}\left(\mathrm{H}_{5} \mathrm{~N} 8\right)$ in wild and domestic birds in the Republic of Korea, and Taiwan, and the event suggested re-introduction of the virus via wild birds migrating back to Europe for overwintering.
Outbreaks in wild birds

From 30 October to 6 December 2016, 14 European countries (Austria, Croatia, Denmark, Finland, France, Germany, Hungary, the Netherlands, Poland, Romania, Russia, Serbia, Switzerland, and Sweden) as well as Egypt, India, Iran, and Israel reported HPAI A( $\left.{ }_{5} \mathrm{~N} 8\right)$ outbreaks in domestic poultry or detections in wild or zoo birds (Figure) [2]. Tunisia and Ukraine reported HPAI $A\left(\mathrm{H}_{5}\right)$ outbreaks suspected to be $A\left(\mathrm{H}_{5} \mathrm{~N} 8\right)$. Since the first finding in October, the virus spread rapidly across central Europe. It mostly affected wild water birds, but also birds of prey that feed on dead birds' carcasses. Infections of the latter indicate a recent introduction into the local resident bird population.

\section{Outbreaks in poultry holdings}

In 2016, outbreaks in poultry holdings were reported from Austria, Denmark, France, Germany, Hungary, the Netherlands, Poland and Sweden [2]. This resembles the situation in the northern hemisphere winter 2014/15 when a virus of the same clade 2.3.4.4 caused outbreaks in six European countries (Germany [3,4], Italy [5], Hungary [6], the Netherlands [7], Sweden and the United Kingdom [8]), mainly in closed poultry holdings, and sporadic detections in wild birds and a zoo $[2,3]$. Although the viruses belong to the same 
Detection of highly pathogenic avian influenza virus $\mathrm{A}(\mathrm{H} 5 \mathrm{~N} 8)$ in wild birds and poultry, Europe and neighbouring regions, November 2014 to February 2015 and October to December $2016^{\mathrm{a}}$

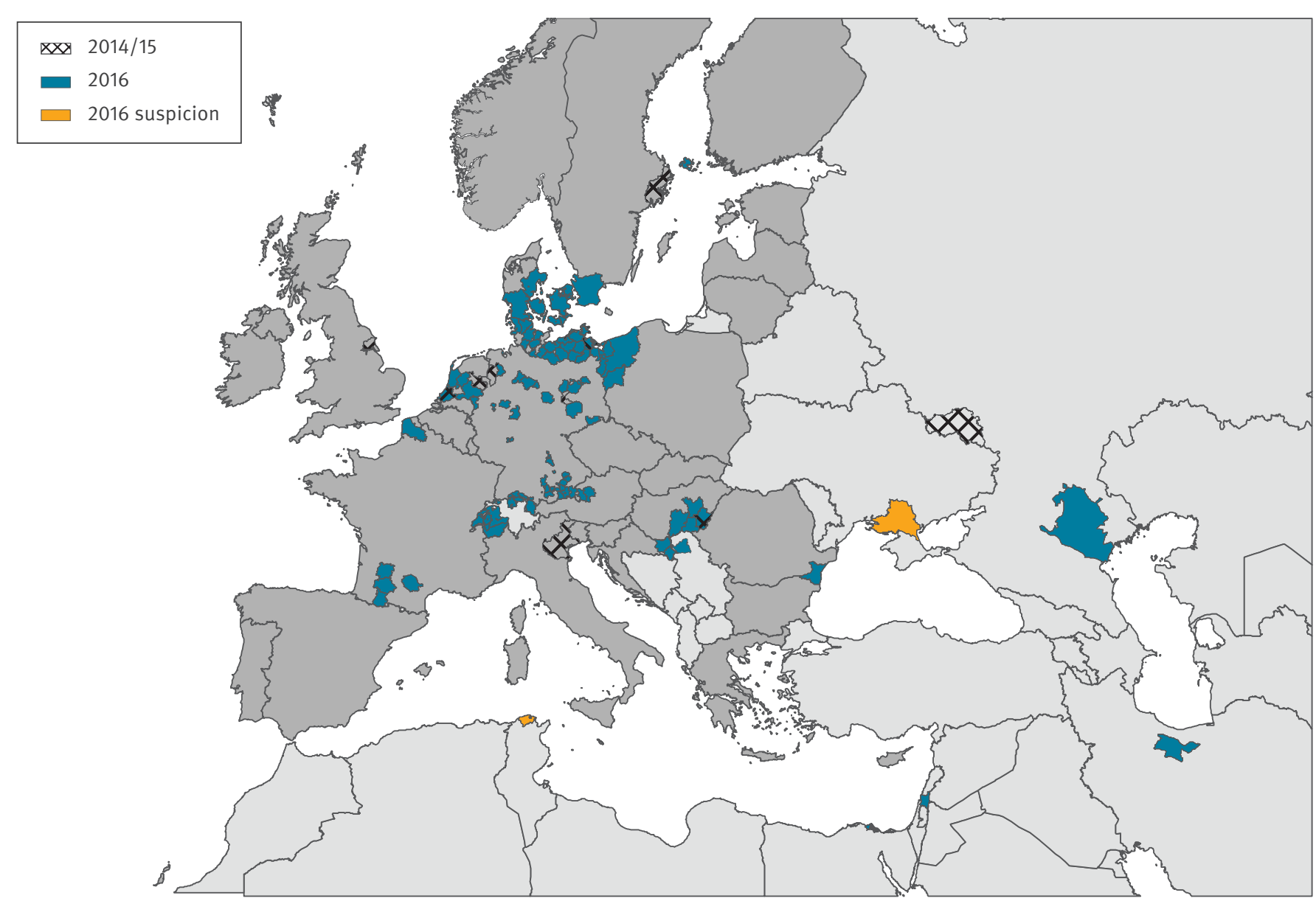

EU/EEA: European Union/European Economic Area.

a The map displays the situation as at 6 December 2016. Dark grey represents the EU/EEA.

genotype clade, viruses during the 2014/15 outbreak belonged to a different group of clade 2.3.4.4, group A (Buan-like), while the current 2016 viruses cluster in clade 2.3.4.4 group B (Gochang-like).

This report presents critical points identified during the HPAI $A\left(\mathrm{H}_{5} \mathrm{~N}_{1}\right)$ and $\mathrm{A}\left(\mathrm{H}_{5} \mathrm{~N} 8\right)$ outbreaks in 2014/15 for preparedness, communication and public as well as animal health recommendations and measures to contain outbreak of avian influenza.

\section{Potential risks to human health}

No human cases of influenza $\mathrm{A}\left(\mathrm{H}_{5} \mathrm{~N} 8\right)$ virus infection have been reported despite large numbers of people being occupationally exposed while managing the avian outbreaks, thus the risk for humans is considered very low [9]. This contrasts with the risk of bird-tohuman transmission of influenza $\mathrm{A}\left(\mathrm{H}_{5} \mathrm{~N}_{1}\right)$ and is likely due to $\mathrm{A}\left(\mathrm{H}_{5} \mathrm{~N} 8\right)$ receptor-binding properties with the latter virus being better adapted to avian-like receptors than human-like receptors $[8,10-12]$. Although the sequence information available for the haemagglutinin and neuraminidase proteins of recent $\mathrm{A}\left(\mathrm{H}_{5} \mathrm{~N} 8\right)$ isolates does not show any evolution towards increased affinity for humans, these viruses should be closely monitored for any adaptation [13]. The non-structural protein (NS) gene of the $\mathrm{A}\left(\mathrm{H}_{5} \mathrm{~N} 8\right)$ virus detected in a wild sea duck, common Goldeneye, in Sweden in mid-November is truncated (217aa) and reassortment in polymerase acidic (PA) and nucleoprotein (NP) genes has been observed compared to those viruses detected earlier in June in Tyva (S. Zohari, personal communication, December 2016; sequences available in GISAID: EPI863862-69; National Veterinary Institute; Uppsala, Sweden A/Common Goldeneye/Sweden/ SVA161117KU0322/SZ0o02165/2016).

Influenza viruses undergo constant reassortment. Recent human cases of influenza $\mathrm{A}\left(\mathrm{H}_{5} \mathrm{~N} 6\right)$ reported from China illustrate how $\mathrm{A}\left(\mathrm{H}_{5}\right)$ viruses belonging to the same clade 2.3.4.4 as $\mathrm{A}\left(\mathrm{H}_{5} \mathrm{~N} 8\right)$ viruses, can gain the ability to infect humans without any of the major 


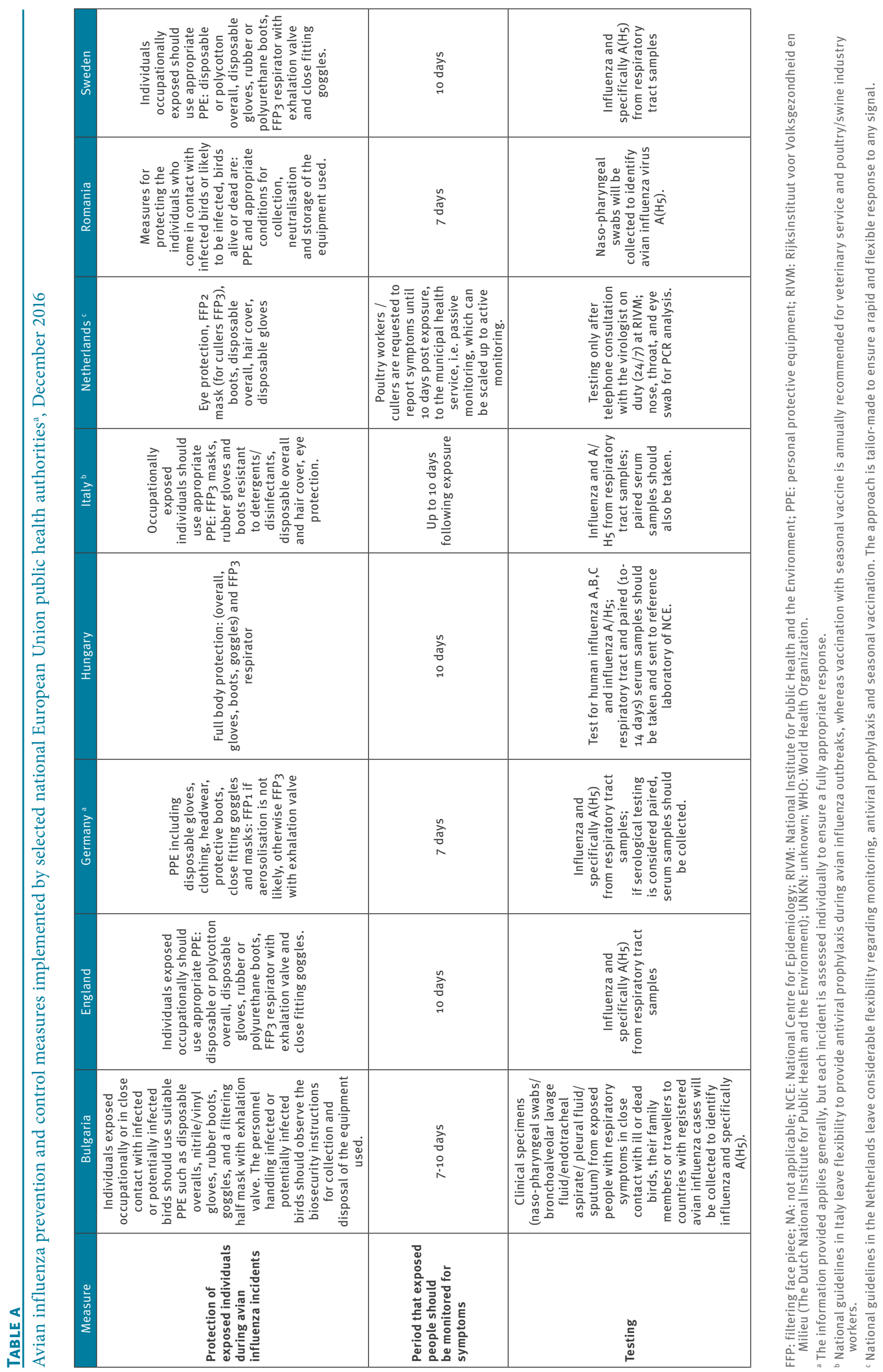



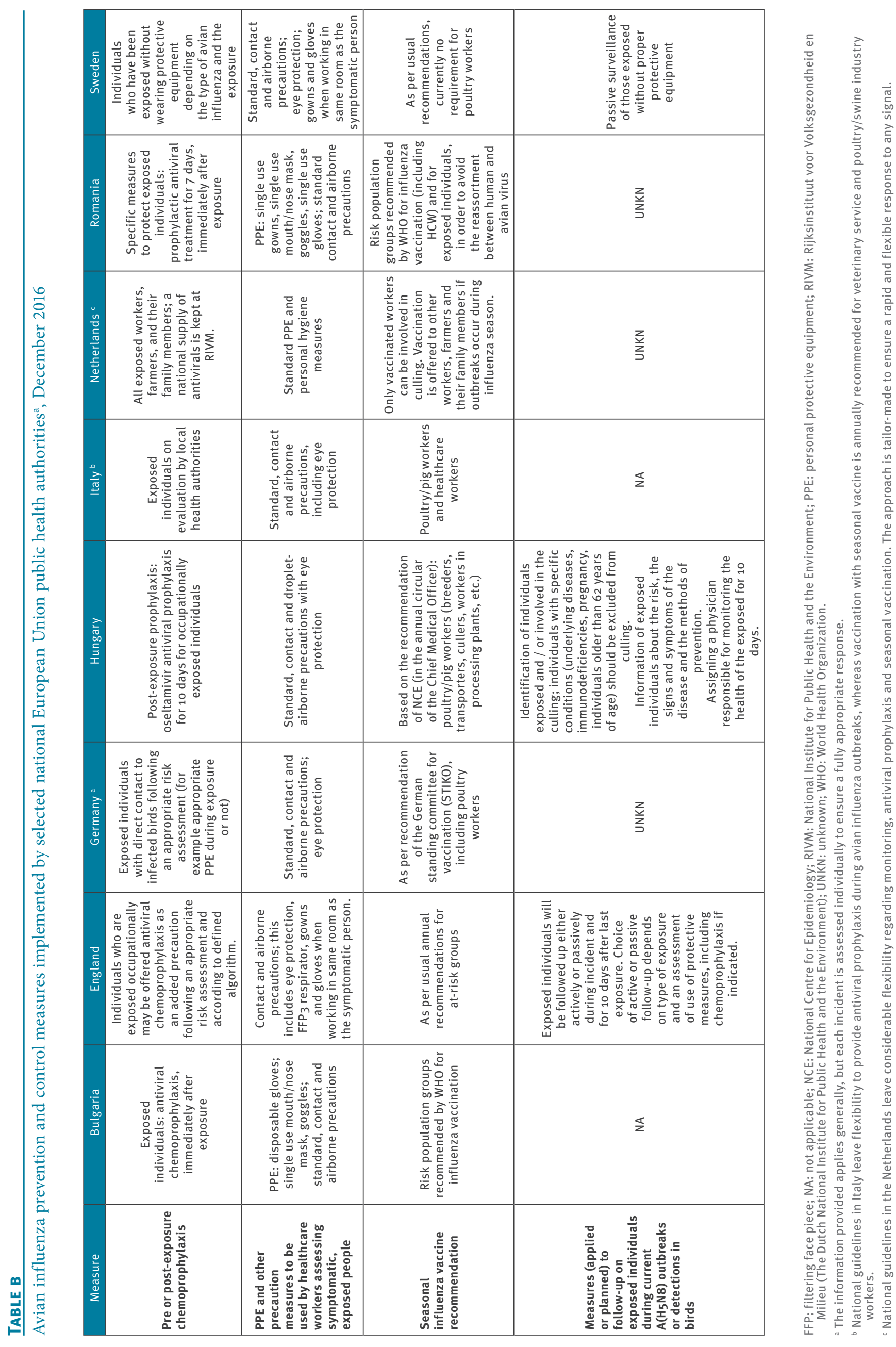


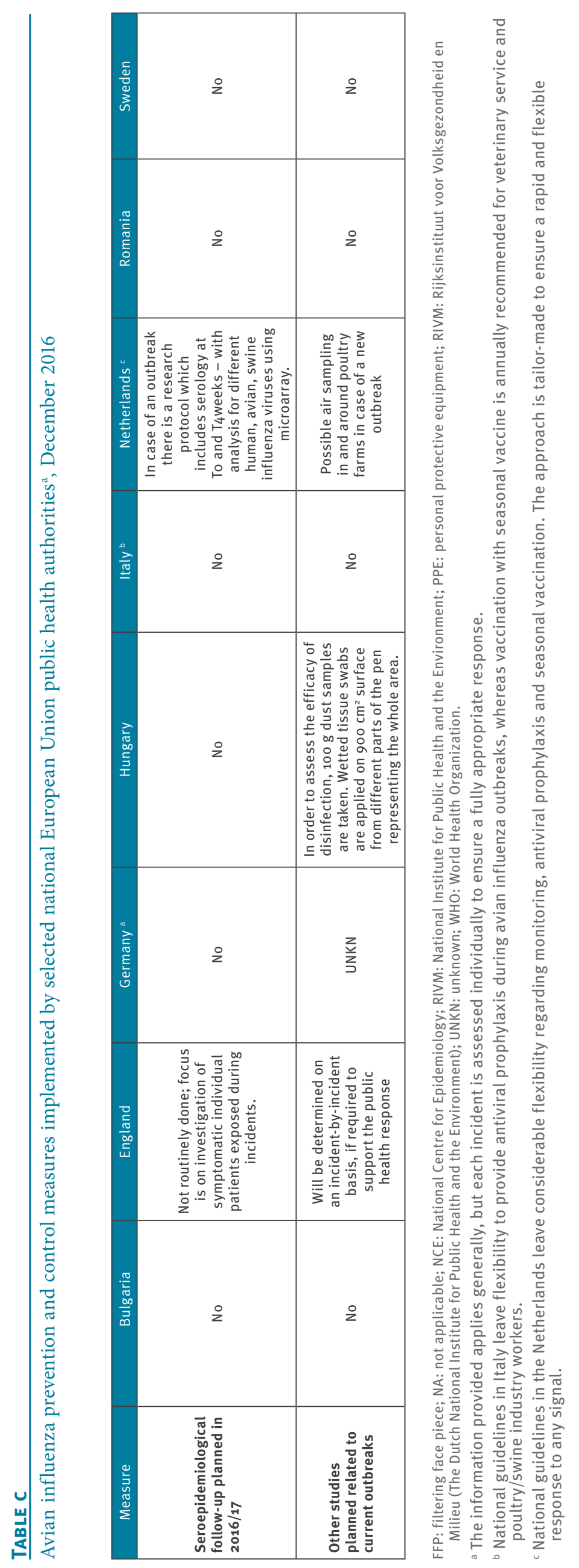


adaptation processes referred to above. The current properties of the virus are not suggestive of pandemic risk. Still, the likely lack of immunity in humans against $\mathrm{A}\left(\mathrm{H}_{5} \mathrm{~N} 8\right)$ and its increasing geographic distribution and incidence in animals justify constant monitoring of outbreaks in birds. Current concerns among veterinarians include the potential ability of $\mathrm{A}\left(\mathrm{H}_{5} \mathrm{~N} 8\right)$ to infect mammals such as cats and dogs: thus precautions should be put in place to minimise the risk of exposure for these animals.

\section{Available guidance on protective measures}

Although the risk of human infection is considered very low [14], most of the available national guidance documents recommend a number of risk mitigation measures to minimise exposure. They target different groups: (i) for the general population recommendations are to avoid exposure to potentially infected birds by not touching dead wild birds, and instead inform local veterinary authorities; (ii) local public and veterinary health authorities are recommended to limit the number of individuals exposed to birds suspected or confirmed to have HPAl; and (iii) individuals exposed occupationally are recommended to use appropriate personal protective equipment (PPE).

\section{Experiences from 2014/15 outbreaks and measures in 2016}

In October 2015, animal and public health experts involved in the $\mathrm{HPAI} A\left(\mathrm{H}_{5} \mathrm{~N}_{1}\right)$ and $\mathrm{A}\left(\mathrm{H}_{5} \mathrm{~N} 8\right)$ outbreaks in Europe in 2014/15, reviewed relevant national protocols available in European Union/European Economic Area (EU/EEA) countries, actions implemented and lessons learnt, in a workshop organised by the European Centre for Disease Prevention and Control (ECDC) [15].

The Table summarises key recommendations from selected public health authorities that managed avian influenza outbreaks in recent years and are valid in 2016. Generally they contain strict use of PPE when handling potentially infected birds, carcasses or other material, with some flexibility based on the local risk assessment in some countries. Post-exposure prophylaxis with neuraminidase inhibitors is advised, often based on individual clinical assessment or local risk assessment. Some, but not all countries recommend pre-exposure prophylaxis that is to be continued during and after exposure. All countries recommend follow-up, passive or active, of those exposed, for development of symptoms for the duration of the maximum incubation period estimated to be around 7-10 days. Exposed people with influenza-like symptoms according to the EU case definition [16] should immediately be tested for influenza virus infection, preferably using lower respiratory tract specimens and including $\mathrm{H}_{5}$-specific tests. Healthcare workers managing suspect human cases should take appropriate contact and airborne precaution measures (Table).

The experts concluded that the actions taken during the $2014 / 15$ outbreaks were adequate to prevent human cases, but some challenges and discrepancies were noted. There was agreement that timely sharing of information between the animal and human health sectors as well as between countries is crucial for an appropriate and early response. Intersectoral communication should also continue between outbreaks to foster cooperation at national level. Most countries appear to use a maximum level of precaution during incidents rather than basing precautions on a careful risk assessment, and experts concur whether this was the most efficient approach. Although a general overview of published evidence was considered useful, risk should be assessed locally.

Recommendations on use of antivirals or seasonal vaccines differed between countries. Some challenges were encountered when post-exposure prophylaxis was recommended, but sufficient antivirals were not immediately available. The experts suggested that rapid availability of antivirals in each country should be reviewed and ensured.

Recommendations for seasonal influenza vaccination of poultry workers in general differ between countries. Seasonal influenza vaccination of exposed individuals during an outbreak was suggested in most countries to avoid co-infection with seasonal and avian influenza viruses which could be followed by reassortment events. However, England considered vaccination with seasonal influenza vaccine during an avian influenza outbreak as being too late for exposed individuals to develop an antibody response necessary for individual protection.

Active follow-up of exposed individuals is resourcedemanding and requires a risk assessment. Suggestions from the meeting were to develop a tool to track and trace information on detections and outbreaks in animals as well as related human exposure and follow-up measures, in real time.

Streamlined messages based on evidence and targeted to those concerned are necessary. Communication barriers i.e. language were identified as reason for failure to follow up exposed mobile and migrant workers on poultry farms. This could be remedied by providing leaflets in different languages.

Large farms might have better safety and training standards than small farms, but response capacity and timeliness during outbreaks may still be insufficient.

Rapid communication and sharing of the viral genetic information is important to estimate the reliability of the PCR-based $\mathrm{A}\left(\mathrm{H}_{5}\right)$ HA gene detection applied in each country/region and antiviral treatment efficacy.

\section{Conclusions}

Humans have been and will be exposed to influenza $A\left(\mathrm{H}_{5} \mathrm{~N} 8\right)$ virus from infected birds, their carcasses or contaminated material in the coming weeks in Europe. 
Although no human cases of influenza $\mathrm{A}\left(\mathrm{H}_{5} \mathrm{~N} 8\right)$ have been documented, expert advice is that precautionary measures should be taken to minimise human exposure and possible infections. Relevant guidance and protection measures have proven sufficient during the avian influenza outbreaks in 2014/15 but were critically reviewed and adjusted where necessary. Well-designed follow-up studies among the exposed would help to document the (lack of) risk from $\mathrm{A}\left(\mathrm{H}_{5} \mathrm{~N} 8\right)$ to humans and the effectiveness of control measures.

Timely communication between the animal and human health sectors is vital to enable a rapid, effective and efficient response to the ongoing outbreaks. Any human infection with a novel influenza subtype should trigger an immediate international notification through the International Health Regulations (IHR) mechanism and the EU Early Warning and Response System.

\section{Acknowledgements}

We acknowledge the authors, originating and submitting laboratories of the sequences from GISAID's EpiFlu Database. The submitter of data may be contacted directly via the GISAID website www.gisaid.org.

The authors are grateful to Kaja Kaasik Aaslav for her great support in monitoring avian influenza situation.

\section{Conflict of interest}

None declared.

\section{Authors' contributions}

All authors provided information on public health measures in their respective country, participated in the meeting referred to in the article, contributed to the article and approved the final version.

Cornelia Adlhoch coordinated the work, interpreted the data and led the writing of the article.

\section{References}

1. Food and Agriculture Organization (FAO) of the United Nations. $\mathrm{H}_{5} \mathrm{~N} 8$ highly pathogenic avian influenza (HPAl) of clade 2.3.4.4 detected through surveillance of wild migratory birds in the Tyva Republic, the Russian Federation - potential for international spread 2016. Rome: FAO. [Accessed 11 Nov 2016]. Available from: http://www.fao.org/3/a-i6113e.pdf.

2. World Organisation for Animal Health (OIE). Update on highly pathogenic avian influenza in animals (type $\mathrm{H}_{5}$ and $\mathrm{H}_{7}$ ). Paris: OIE. [Accessed 5 Dec 2016]. Available from: http://www.oie.int/ animal-health-in-the-world/update-on-avian-influenza/.

3. Conraths FJ, Sauter-Louis C, Globig A, Dietze K, Pannwitz G, Albrecht K, et al. Highly Pathogenic Avian Influenza $\mathrm{H}_{5} \mathrm{~N} 8$ in Germany: Outbreak Investigations. Transbound Emerg Dis. 2016;63(1):10-3. DOI: 10.1111/tbed.12443 PMID: 26519355

4. Harder T, Maurer-Stroh S, Pohlmann A, Starick E, HörethBöntgen D, Albrecht K, et al. Influenza A(H5N8) Virus Similar to Strain in Korea Causing Highly Pathogenic Avian Influenza in Germany. Emerg Infect Dis. 2015;21(5):860-3. DOI: 10.3201/ eid2105.141897 PMID: 25897703

5. Adlhoch C, Gossner C, Koch G, Brown I, Bouwstra R, Verdonck $F$, et al. Comparing introduction to Europe of highly pathogenic avian influenza viruses $A\left(\mathrm{H}_{5} \mathrm{~N} 8\right)$ in 2014 and $A\left(\mathrm{H}_{5} \mathrm{~N}_{1}\right)$ in 2005. Euro Surveill. 2014;19(50):20996. DOI: 10.2807/1560-7917.ES2014.19.50.20996 PMID: 25597538
6. Bányai K, Bistyák AT, Thuma Á, Gyuris É, Ursu K, Marton $\mathrm{S}$, et al. Neuroinvasive influenza virus $\mathrm{A}\left(\mathrm{H}_{5} \mathrm{~N} 8\right)$ in fattening ducks, Hungary, 2015. Infect Genet Evol. 2016;43:418-23. DOI: 10.1016/j.meegid.2016.05.027 PMID: 27215706

7. Bouwstra RJ, Koch G, Heutink R, Harders F, van der Spek A, Elbers AR, et al. Phylogenetic analysis of highly pathogenic avian influenza $A\left(\mathrm{H}_{5} \mathrm{~N} 8\right)$ virus outbreak strains provides evidence for four separate introductions and one betweenpoultry farm transmission in the Netherlands, November 2014. Euro Surveill. 2015;20(26):21174. DOI: 10.2807/1560-7917. ES2015.20.26.21174 PMID: 26159311

8. Hanna A, Banks J, Marston DA, Ellis RI, Brookes SM, Brown IH. Genetic Characterization of Highly Pathogenic Avian Influenza ( $\left.{ }_{5} \mathrm{~N} 8\right)$ Virus from Domestic Ducks, England, November 2014. Emerg Infect Dis. 2015;21(5):879-82. DOI: 10.3201/ eid2105.141954 PMID: 25898126

9. Arriola CS, Nelson DI, Deliberto TJ, Blanton L, Kniss K, Levine MZ, et al. , $\mathrm{H}_{5}$ Investigation Group. Infection Risk for Persons Exposed to Highly Pathogenic Avian Influenza $\mathrm{A} \mathrm{H}_{5}$ Virus-Infected Birds, United States, December 2014-March 2015. Emerg Infect Dis. 2015;21(12):2135-40. DOI: 10.3201/ eid2112.150904 PMID: 26583382

10. Kaplan BS, Russier M, Jeevan T, Marathe B, Govorkova EA, Russell CJ, et al. Novel Highly Pathogenic Avian $A\left(\mathrm{H}_{5} \mathrm{~N}_{2}\right)$ and $A\left(\mathrm{H}_{5} \mathrm{~N} 8\right)$ Influenza Viruses of Clade 2.3.4.4 from North America Have Limited Capacity for Replication and Transmission in Mammals. mSphere. 2016 Mar-Apr;1(2).

11. Richard $M$, Herfst $S$, van den Brand JM, Lexmond $P$, Bestebroer TM, Rimmelzwaan GF, et al. Low Virulence and Lack of Airborne Transmission of the Dutch Highly Pathogenic Avian Influenza Virus $\mathrm{H}_{5} \mathrm{~N} 8$ in Ferrets. PLoS One. 2015;10(6):e0129827. DOI: 10.1371/journal.pone.0129827 PMID: 26090682

12. Pulit-Penaloza JA, Sun X, Creager HM, Zeng H, Belser JA, Maines TR, et al. Pathogenesis and Transmission of Novel Highly Pathogenic Avian Influenza $\mathrm{H}_{5} \mathrm{~N}_{2}$ and $\mathrm{H}_{5} \mathrm{~N} 8$ Viruses in Ferrets and Mice. J Virol. 2015;89(20):10286-93. DOI: 10.1128/ JVI.01438-15 PMID: 26223637

13. United Kingdom (UK) Department for Environment Food and Rural Affairs. Animal \& Plant Health Agency Veterinary \& Science Policy Advice Team - International Disease Monitoring. Highly Pathogenic Avian Influenza $\mathrm{H}_{5} \mathrm{~N} 8$ in Europe, Updated Outbreak Assessment number 3 2016. UK: Department for Environment Food and Rural Affairs. [Accessed 26 Nov 2016]. Available from: https://www.gov.uk/government/uploads/ system/uploads/attachment_data/file/570883/hpai-europeuoa-update3.pdf

14. European Centre for Disease Prevention and Control (ECDC). RAPID RISK ASSESSMENT: Outbreaks of highly pathogenic avian influenza $\mathrm{A}\left(\mathrm{H}_{5} \mathrm{~N} 8\right)$ in Europe, updated 18 November 2016. Stockholm: ECDC. 2016. [Accessed 26 Nov 2016]. Available from: http://ecdc.europa.eu/en/publications/Publications/riskassessment-avian-influenza-H5N8-europe.pdf.

15. European Centre for Disease Prevention and Control (ECDC). Avian Influenza Preparedness Workshop. Stockholm: ECDC. [Accessed 5 Dec 2016]. Available from: http://ecdc.europa. eu/en/press/events/_layouts/forms/Event_DispForm. aspx? List $=$ a8926334-8425-4aae-be6a-70f89f9d563c \&ID=348

16. European Centre for Disease Prevention and Control (ECDC). Influenza case definitions. Stockholm: ECDC. [Accessed 5 Dec 2016]. Available from: http://ecdc.europa.eu/en/healthtopics/ influenza/surveillance/Pages/influenza_case_definitions.aspx

\section{License and copyright}

This is an open-access article distributed under the terms of the Creative Commons Attribution (CC BY 4.0) Licence. You may share and adapt the material, but must give appropriate credit to the source, provide a link to the licence, and indicate if changes were made.

This article is copyright of the authors, 2016. 